\title{
The Optimal Reaction Condition for Class Demonstrated Experiment of Methane and Chlorine Substitution Reaction
}

\author{
Yufei Wu, Yu Zhang \\ Chemical and material science \\ college \\ HeBei Normal University \\ ShiJiaZhuang City, P.R.China
}

\author{
Zhongqiang Zhang \\ Department of Applied Chemistry \\ HengShui University \\ HengShui City, P.R.China
}

\author{
Yu Zhang \\ Chemical and material science \\ college \\ HeBei Normal University \\ ShiJiaZhuang City, P.R.China
}

\begin{abstract}
The success rate for class demonstrated experiment of methane and chlorine substitution reaction (MCSR) is very low during the practical teaching process because the conditions for the experiment of MCSR are difficult to control. So the teaching effects were always poor when the experiment was failure. The influence factors were studied in this paper, such as temperature, illumination and the rate for reactant, et al. The optimal reaction condition has been discovered by repeated experiments: The volume rate for Methane and Chlorine is $1: 3$, the reactants were irradiated by a high pressure mercury lamp $(125 \mathrm{~W})$ and the distant is 10 centimeters $(\mathrm{d}=10 \mathrm{~cm})$, and the temperature is in normal temperature. There is a great improvement in the effect for class demonstrated experiment of MCSR at the abovementioned conditions.
\end{abstract}

Keywords-component; methane; chlorine; substitution reaction; volume rate; illumination

\section{INTRODUCTION}

The class demonstrated experiment of MCSR is an important part in several chemistry textbooks of senior high school in China [1-5]. Not only will the students be influenced in study for the properties and structures of methane and other alkanes, but also whole organic chemistry. The success rate for the class demonstrated experiment is very low during the practical teaching process because of difficult to control reaction conditions, such as temperature, illumination and the rate for reactant, et al. It is the key to improve the effect of teaching to find suitable conditions for the experiment of MCSR. Therefore, a few researches in this field have been reported [6-8].

\section{EXPERIMENTAL SECTION}

\section{A. Materials and Methods}

All chemicals and reagents were used as received from commercial sources without further purification. The experimental methods were the same as the chemistry textbook of senior high school in China [1]. The figure 1, 2 and 3 are the preparation instruments for $\mathrm{CH}_{4}, \mathrm{Cl}_{2}$ and the tester for MCSR, respectively. The reduced volume in measuring cylinder shows the reaction degree for the experiment of MCSR. The gas mixture volume is smaller and it means the higher reaction degree.

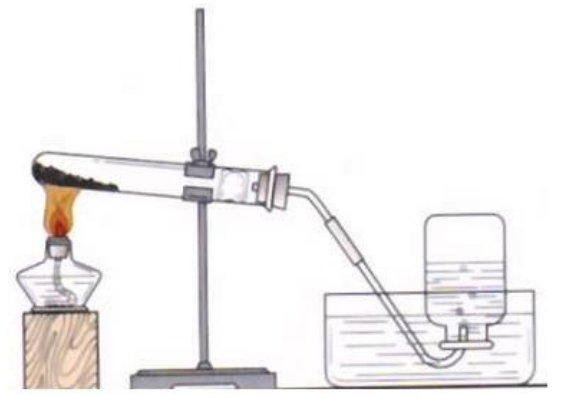

FIGURE 1. THE PREPARATION INSTRUMENT FOR $\mathrm{CH}_{4}$

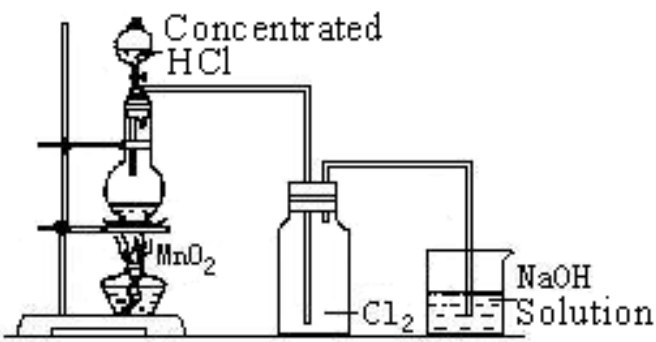

FIGURE 2. THE PREPARATION INSTRUMENT FOR $\mathrm{Cl}_{2}$

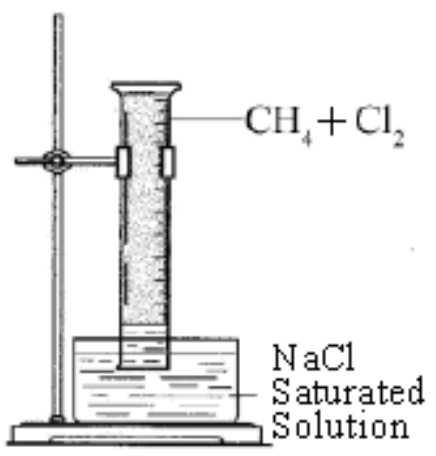

FIGURE 3.

THE TESTER FOR EXPERIMENT OF MCSR 


\section{B. Result and Discussion}

\section{1) The Influence for Experiment of MCSR by Temperature}

The experiments of MCSR are under different temperature, for example $15^{\circ} \mathrm{C}, 20^{\circ} \mathrm{C}, 25^{\circ} \mathrm{C}$, and other reaction conditions are dispersion sunlight and the volume rate for Methane and Chlorine is $1: 1$. The figure 4 shows that the ratios of reduced volume in reaction system are variation with reaction time under different temperature.

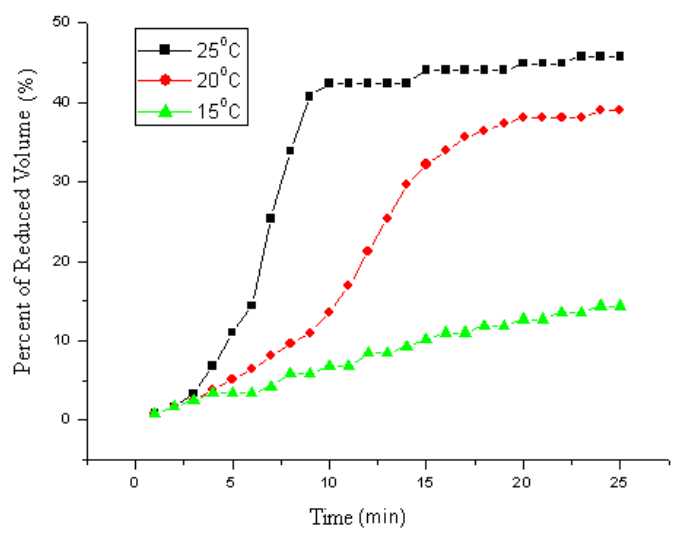

FIGURE 4. THE RATIOS OF REDUCED VOLUME IN REACTION SYSTEM ARE VARIATION WITH REACTION TIME UNDER DIFFERENT TEMPERATURE

The reaction type for MCSR is the free radical reaction [9]. As shown in Figure 4, when the experiment of MCSR is under $25^{\circ} \mathrm{C}$, the stage for chain initiation is about 1 to 2 minutes. The reaction speed is accelerated at the period for about 3 to 6 minutes, and the volume of reaction mixture is decrease sharply. It is typical chain growth stage. Then the reaction comes to chain termination stage. The reaction speed for experiments of MCSR are slower when the temperatures are $15^{\circ} \mathrm{C}$ or $20^{\circ} \mathrm{C}$, so the reaction speed for experiments of MCSR is rapider as the reaction temperatures are higher. In fact, the experiment results show the same conclusion when the volume rate for Methane and Chlorine is different to the above-mentioned conditions.

\section{2) The Influence for Experiment of MCSR by Illumination}

The experiments of MCSR that have been finished in the classroom are under different illumination, for example indoor fluorescent lamp, dispersion sunlight, $125 \mathrm{~W}$ high pressure mercury $\operatorname{lamp}(\mathrm{d}=10 \mathrm{~cm})$, and other reaction conditions are $20^{\circ} \mathrm{C}$ and the volume rate for Methane and Chlorine is 1:1. The figure 5 shows that the ratios of reduced volume in reaction system are variation with reaction time under different illumination.

As shown in Figure 5, the chemical reaction courses are very different under different illumination. The reaction speed for MCSR is very slow under indoor fluorescent lamp, and it is no significant change in the whole course of chemical reaction. The three progresses for chain initiation stage, chain growth stage and chain termination are not clearly observed. The reaction speed for MCSR is slower under dispersion sunlight. The three progresses for chain initiation stage, chain growth stage and chain termination are clearly observed when $125 \mathrm{~W}$ high pressure mercury lamp $(\mathrm{d}=10 \mathrm{~cm})$ is as illumination. The chain initiation stage is about 0 to 2 minutes, the chain growth stage is about 2 to 4 minutes and the volume of reaction mixture is decrease sharply, and the chain termination is about 4 to 6 minutes.

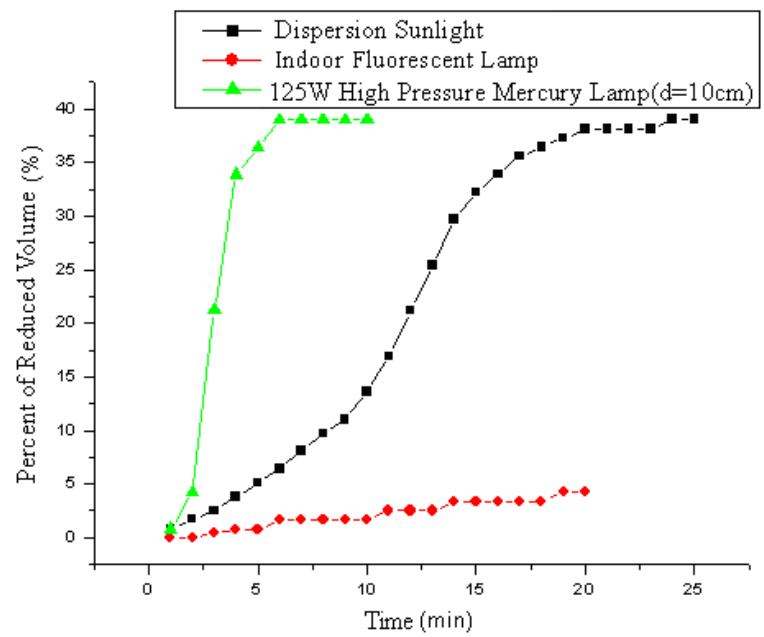

FIGURE 5. THE RATIOS OF REDUCED VOLUME IN REACTION SYSTEM ARE VARIATION WITH REACTION TIME UNDER DIFFERENT ILLUMINATION

3) The Influence for Experiment of MCSR by the Rate for Reactant

The experiments of MCSR are under different the volume rate for Methane and Chlorine, for example1:1, 1:3, 1:4, 1:6 and $1: 8$, and other reaction conditions are $20^{\circ} \mathrm{C}$ and $125 \mathrm{~W}$ high pressure mercury lamp $(\mathrm{d}=10 \mathrm{~cm})$. The figure 6 shows that the ratios of reduced volume in reaction system are variation with reaction time under different the volume rate for Methane and Chlorine.

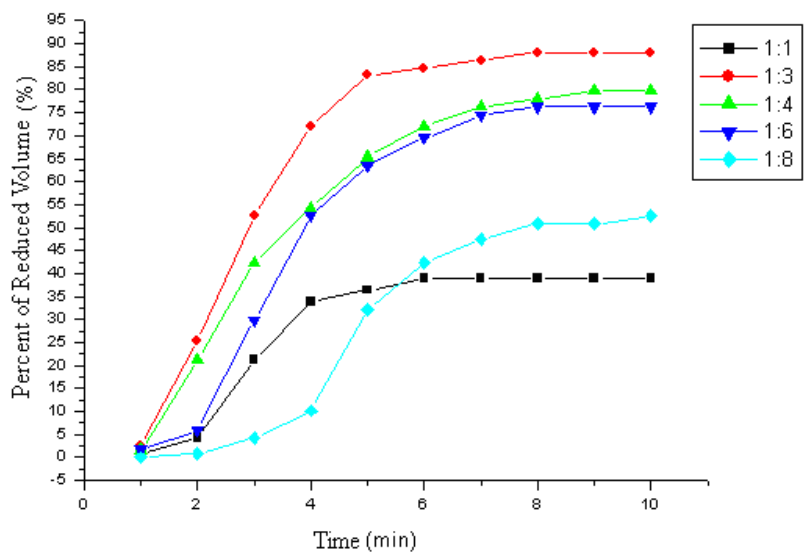

FIGURE 6. THE RATIOS OF REDUCED VOLUME IN REACTION SYSTEM ARE VARIATION WITH REACTION TIME UNDER DIFFERENT THE VOLUME RATE FOR METHANE AND CHLORINE

As shown in Figure 6, the time for chain initiation stage is all short at the course of chemical reaction when the volume rates for Methane and Chlorine are in all the above-mentioned proportions. But the chain growth stages are obvious difference, 
when the volume rates for Methane and Chlorine are 1:1, 1:3, $1: 4,1: 6$ and $1: 8$, the stages are about 2 to 6 minutes, 1 to 5minutes, 1 to 9 minutes, 2 to 8 minutes and 2 to 8 minutes, respectively. The above-mentioned reactions all enter the chain termination stages when the progress of chemical reaction is about 10 minutes. The reduced volume in reaction system are $39.0 \%, 88.1 \%, 79.0 \%, 76.0 \%$ and $52.5 \%$ respectively when the volume rates for Methane and Chlorine are 1:1, 1:3, 1:4, 1:6 and $1: 8$. It is worth noting that the reduced volume in reaction system is the rapidest in Figure 6 when the volume rates for Methane and Chlorine is 1:3. It suggests that the speed for experiment of MCSR is the rapidest when the volume rates for Methane and Chlorine is 1:3.

4) The Influence for Experiment of MCSR under Direct Irradiation from Sunlight

All the chemistry textbooks of senior high school in China have warned not to do the experiment of MCSR under direct irradiation from sunlight because of explosion. But no one illuminate how dangerous it is and what effective methods can be taken to avoid this condition. The case has been researched through a few experiments. The experiments of MCSR are under direct irradiation from sunlight, and other reaction conditions are $20{ }^{\circ} \mathrm{C}$ and the volume rate for Methane and Chlorine is $1: 1,1: 3,1: 4,1: 6$ and $1: 8$.

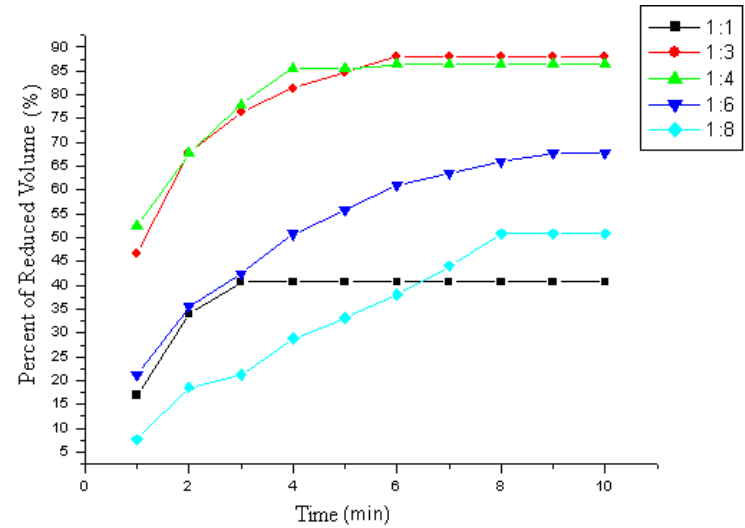

FIGURE 7. THE INFLUENCE FOR EXPERIMENT OF MCSR UNDER DIRECT IRRADIATION FROM SUNLIGHT $\left(20^{\circ} \mathrm{C}\right)$

As shown in Figure 7, the reaction speed for experiments of MCSR is rapidest when the volume rate for Methane and Chlorine is $1: 3$ or $1: 4$. The experimental phenomena are similar when the experiments of MCSR are under direct irradiation from sunlight and other reaction conditions are $20^{\circ} \mathrm{C}$ and the volume rate for Methane and Chlorine is 1:3 or 1:4. The reaction was happened at once and a little blast noise was brought forth from tester. The reduced volume in reaction system is $75 \%$ and $73 \%$ respectively, and a large amount of black substance was obvious. The black substance is tiny particle of carbon. But no explosion was broken out. So the experiment of MCSR is safety under direct irradiation from sunlight when the temperature is below $20^{\circ} \mathrm{C}$.

\section{CONCLUSION}

The proper methods and conditions for the experiment of MCSR as class demonstrated experiment have been found after some trial-and-error experiments. The methods are the same as the chemistry textbook of senior high school in China [1]. The optimal reaction condition is discovered by repeated experiments: The volume rate for Methane and Chlorine was $1: 3$, the reactants were irradiated by a $125 \mathrm{~W}$ high pressure mercury lamp $(\mathrm{d}=10 \mathrm{~cm})$, and the temperature is in normal temperature. The experiment of MCSR has more distinct advantages at the condition, such as the chain growth stage is only 1 to 5 minutes, in other words, the speed for MCSR is very rapid and the experimental phenomena are evidence. It is important that the conditions for the experiment of MCSR are easily to control because the course of chemical reaction cannot be influenced by climate. So there is a great improvement in the effect for class demonstrated experiment of MCSR. Otherwise, the experiment of MCSR is safety under direct irradiation from sunlight when the temperature is below $20^{\circ} \mathrm{C}$.

\section{ACKNOWLEDGMENT}

This work was supported by the educational science planning project for "the 11th five-year plan" in HeBei province (No.06020578).

\section{REFERENCES}

[1] Teaching Material Institute of People Education Publishing Company, Chemistry(Obligatory Course 2). People Education Publishing Company, Beijing, 2007.

[2] Beijing Normal University Chief Editor Committee of Conventional Test Teaching Material of State Basic Education Course, Chemistry(Obligatory Course 2). Shandong Science and Technology Publishing Company, Jinan, 2007.

[3] Z, H. Wang, Chemistry (Obligatory Course 2). Jiangsu Education Publishing Company, Nanjing, 2006.

[4] X.T. Wang, Chemical Experiment Teaching Research. Higher Education Publishing Company, Beijing, 1990.

[5] Teaching and Research Section for Chemistry of People Education Publishing Company, Chemistry(Obligatory Course). People Education Publishing Company, Beijing, 2003.

[6] B.Q. Lu, H.Y. Tan, "Rediscovery Improvement Experiment for Methane and Chlorine Substitution Reaction", Teaching Instruments and Experiment, vol.28, pp.15-16, 2012

[7] Y.J. Liu, "Improvement Experimental Installation for Methane and Chlorine Substitution Reaction", Chemical Education, issue 1, pp.42-43, 2011

[8] R.H. Zhang, "Improvement Experiment for Methane and Chlorine Substitution Reaction", Experiment and Innovation Thinking, issue 7, pp.17-18, 2010

[9] S.C. Xu, Organic Chemistry. Higher Education Publishing Company, Beijing,2000. 